\title{
Effect of conductive substrate (working electrode) on the morphology of electrodeposited $\mathrm{Cu}_{2} \mathrm{O}$
}

\author{
Ayman S ELmezayyen ${ }^{1,2}$, Shian Guan ${ }^{2}$, Fikry M Reicha ${ }^{1}$, \\ Ibrahim M El-Sherbiny ${ }^{3}$, jianming Zheng ${ }^{2}$ and Chunye $\mathrm{Xu}^{2}$ \\ ${ }^{1}$ Biological Advanced Materials, Physics Department, Faculty of Science, Mansoura University, \\ Mansoura, Egypt \\ ${ }^{2}$ Department of Materials Physics and Chemistry, Hefei National Laboratory for Physical Sciences at \\ Microscale, University of Science and Technology of China, Hefei 230026, People's Republic of China \\ ${ }^{3}$ Zewail City of Science and Technology, Center for Materials Science, Giza, Egypt \\ E-mail: ielsherbiny@zewailcity.edu.eg and Chunye@ustc.edu.cn
}

Received 12 November 2014, revised 11 February 2015

Accepted for publication 3 March 2015

Published

\begin{abstract}
$\mathrm{Cu}_{2} \mathrm{O}$ thin films were electrodeposited from a $\mathrm{Cu}(\mathrm{II})$ acetate solution containing $0.02 \mathrm{M}$ Copper(II) acetate $\left(\mathrm{Cu}(\mathrm{OAc})_{2}\right)$ and 0.1 Msodium acetate $(\mathrm{NaOAc})$ at $\mathrm{pH} 5.6$, using three different working conductive electrodes with approximately the same square resistance -indium doped tin oxide glass (ITO/Glass), fluorine-doped tin oxide glass (FTO/Glass), and Indium doped tin oxide Polyethylene terephthalate (ITO/PET) — under identical conditions using a common growth condition. The $\mathrm{Cu}_{2} \mathrm{O}$ thin films werecharacterized by means ofscanning electron microscopy (SEM), x-raydiffraction (XRD), current density versus growth time for $\mathrm{Cu}_{2} \mathrm{O}$ films, and electrochemical impedance spectroscopy (EIS). The results showed that the choice of substratematerials hasa crucial role in controlling of $\mathrm{Cu}_{2} \mathrm{O}$ growth. The charge transfer resistance (Rct) of $\mathrm{FTO} / \mathrm{Glass}-\mathrm{Cu}_{2} \mathrm{O}$ exhibits the lowest value; this means that $\mathrm{FTO} / \mathrm{Glass}-\mathrm{Cu}_{2} \mathrm{O}$ possess the highest electron transfer efficiency. $\mathrm{All}^{\mathrm{Cu}} \mathrm{U}_{2} \mathrm{O}$ films showed n-type semiconductor characteristic with charge carrier densities varying between $1.4 \times 10^{18}-1.2 \times 10^{19} \mathrm{~cm}^{-3}$
\end{abstract}

Keywords: morphology, $\mathrm{Cu}_{2} \mathrm{O} \underline{\underline{\text { thin }} \mathrm{lms}}$, electrodeposition

S Online supplementary data available from stacks.iop.org/000/000/000

(Some figures may appear in colour only in the online journal)

\section{Introduction}

Current advances in materials have almost every fundamental to modern science and technology. On the nano-/ micro-scale, dominion over structure, size, and morphology of a material enables control of its properties and enhancement of its utility for a given application. Among various metal oxide materials, cuprous oxide $\left(\mathrm{Cu}_{2} \mathrm{O}\right)$ semiconductors remarkably are an interest area of research for a several fields. Nowadays, the promising applications of $\mathrm{Cu}_{2} \mathrm{O}$ mainly focus on chemical sensors, photocatalysis, lithium ion batteries and catalysis. Also, there are nascent applications that demandoptical transparency and mechanical flexibility for a variety of optoelectronic and photovoltaic application [1-4].

It has increasingly attracted attention due to its widespread availability, environmental safety, low costs and compatibility with diverse substrates [5]. $\mathrm{Cu}_{2} \mathrm{O}$ has been developed using various techniques-for example, sputtering [6], chemical oxidation [7], thermal oxidation [8], electrodeposition [9], chemical vapor deposition [10], etc. -but the growth of $\mathrm{Cu}_{2} \mathrm{O}$ thin film using electrodeposition has been noted as remarkable 
achievement, becoming a worldwide topic of interest. This technique has the strengths and advantages compared to other semiconductor growth technique. This preference due to its simplicity, scalability, manufacturability, and as a low cost deposition technology that can easily be carried out in normal laboratory conditions [11].

In the past decades, many efforts were used to innovate the crystallization of cuprous oxide thin film with different aspects including morphology, size, and structure using electrodeposition has attracted much attention Because fascinating properties might be accomplished, $\mathrm{Cu}_{2} \mathrm{O}$ can be tuned into various morphologies, such as cubes [12], truncated, octahedral, facets, polyhedral [13], flowerlike [14], etc. By focusing on synthesis of cuprous oxide thin film using theelectrodepostion technique, authors tried to control the morphology of the deposited thin film depending on the applied potential [15], additives [16], temperature, $\mathrm{pH}$ [15], concentration, and type of electrolyte [17]. To the best of our knowledge, there are a few articles working on investigating the effect of conductive substrate-electrode on which the $\mathrm{Cu}_{2} \mathrm{O}$ deposited, Osherov et al studied the Influence of ITO Electrode Surface Composition on the Growth of Electrodeposited $\mathrm{Cu}_{2} \mathrm{O}$ Thin Films [18]. Also Liu et al reported the effect of the substrates include indium tin oxide film coated glass, n-Si wafer with (001) orientation and $\mathrm{Au}$ film evaporated onto Si substrate onthe structural and optical properties of electrodeposited $\mathrm{Cu}_{2} \mathrm{O}$ films [19].

Therefore, it is highly desirable to study the effect of the transparent and/or flexible working conductive substrate on the fabrication and the physical properties $\mathrm{Cu}_{2} \mathrm{O}$ metal oxide.

In this paper, $\mathrm{Cu}_{2} \mathrm{O}$ thin films are electrodeposited on three different working conductive substrates indium doped tin oxide glass (ITO/Glass), fluorine-doped tin oxide glass (FTO/ Glass), and Indium doped tin oxide Polyethylene terephthalate (ITO/PET), under identical conditions using a common growth solution. We investigated how the surface morphology of the deposited film was affected by the type of conductive substrate.

\section{Experimental}

\subsection{Materials}

Copper(II) acetate $\left(\mathrm{Cu}(\mathrm{OAc})_{2}, 99 \%\right.$ purity), sodium acetate (NaOAc, >98\%), and acetic acid (HOAc, used to adjust solution $\mathrm{pH}$ value., $99 \%$ purity) were obtained fromSigma Aldrich, and used as purchased. The solutions used in this research were prepared with deionized water further purified with a Millipore Milli-Q purification system.

\subsection{Deposition of $\mathrm{Cu}_{2} \mathrm{O}$ films}

The electrodeposition was performed with a standard three electrode system (CHI-660D; CH Instruments, Shanghai, China). Three different conductive substrates with approximately the same resistivity-Indium doped tin oxide glass (ITO/Glass; $13 \Omega / \square$ ), fluorine-doped tin oxide glass (FTO/
Glass; $13.4 \Omega / \square$ ), and Indium doped tin oxide Polyethylene terephthalate (ITO/PET; $15 \Omega / \square$ ) -were used as working electrodes. A platinum sheet and $\mathrm{Ag} / \mathrm{AgCl}$ were respectively used as a counter and reference electrodes. All of the chemicals were used without further purification. Before electrodeposition, the substrates were rinsed with distilled water and then cleaned with ethanol in an ultrasonic set for about $10 \mathrm{~min}$. In our work, $\mathrm{Cu}_{2} \mathrm{O}$ films were electrodeposited in $0.1 \mathrm{M}$ sodium acetate $(\mathrm{NaOAc})$ and $0.02 \mathrm{M} \mathrm{Cu}(\mathrm{OAc})_{2}$ aqueous solutions [20], with $\mathrm{pH}$ adjusted to 5.6 using acetic acid.

\subsection{Characterization}

X-ray diffraction (XRD) patterns of the films were recorded in the $2 \theta$ range from $5^{\circ}$ to $65^{\circ}$ with a $\mathrm{X}$-ray diffractometer (X'Pert PRO; PANalytical B. V., Almelo, Netherlands), where a $\mathrm{Cu} \mathrm{K} \alpha(\mathrm{K} \alpha=1.5406 \AA, 40 \mathrm{kV}, 200 \mathrm{~mA})$ was used as an X-ray source. Mitero-images for all flms were obtained from a seannining electron milieroseope (SEM, Sinion 200, ГLI, Hillsboro, Oregon, USA). Field emission scanning electron microscopy (FESEM) images were obtained using a JEOL JSM- 6700 scanning electron microscope operated at $8.0 \mathrm{kV}$. Electrochemical impedance spectroscopy (EIS) measurements of theprepared films were performed in an acetonitrile solution of $0.1 \mathrm{molL}^{-1}$ lithium perchlorate electrolyte. The (EIS) measurements were performed with a standard three electrode system (CHI-660 D; CH Instruments, Shanghai, China) atperturbation potential of $20 \mathrm{mV}$ with frequency range from $10^{-1}$ $10^{5} \mathrm{~Hz}$. Measurements were typically performed withrespect to the open-circuit potential (OCP). Measurements were performed at room temperature and repeated at least three times. Finally, the type of conductivityand doping concentration of films were obtained through capacitancemeasurements represented in a Mott-Schottky plot using ac amplitudeof $20 \mathrm{mV}$ and a frequency of $1 \mathrm{kHz}$.

\section{Results and discussion}

\subsection{Structure and morphology of $\mathrm{Cu}_{2} \mathrm{O}$ films}

3.1.1. $X R D$. Electrodeposition of $\mathrm{Cu}_{2} \mathrm{O}$ involves two steps: reduction of $\mathrm{Cu}^{2+}$ ions to $\mathrm{Cu}^{+}$ions (equation (1)) and precipitation of $\mathrm{Cu}^{+}$ions to $\mathrm{Cu}_{2} \mathrm{O}$ due to the solubility limitation of $\mathrm{Cu}^{+}$ions (equation (2)) [15].

$$
\begin{gathered}
\mathrm{Cu}^{2+}+\mathrm{e}^{-} \Leftrightarrow \mathrm{Cu}^{2+} \\
2 \mathrm{Cu}^{+}+\mathrm{H}_{2} \mathrm{O} \Rightarrow \mathrm{Cu}_{2} \mathrm{O}+2 \mathrm{H}^{+} \\
2 \mathrm{Cu}^{+}+\mathrm{H}_{2} \mathrm{O}+\mathrm{e}^{-}=\mathrm{Cu}_{2} \mathrm{O}+2 \mathrm{H}^{+}
\end{gathered}
$$

In order to select the appropriate potential for $\mathrm{Cu}_{2} \mathrm{O}$, electrodeposition of $\mathrm{Cu}_{2} \mathrm{O}$ on the three electrodes was performed for $60 \mathrm{~min}$ at room temperature under different deposition potential conditions: $-100,-200,-300,-400$ and $-500 \mathrm{mV}$ versus $\mathrm{Ag} / \mathrm{AgCl}$ electrode. As shown in figure 1, it can be verified by the x-ray diffraction (XRD) spectra obtained from the films electrodeposited on PET/ITO at various potential. 


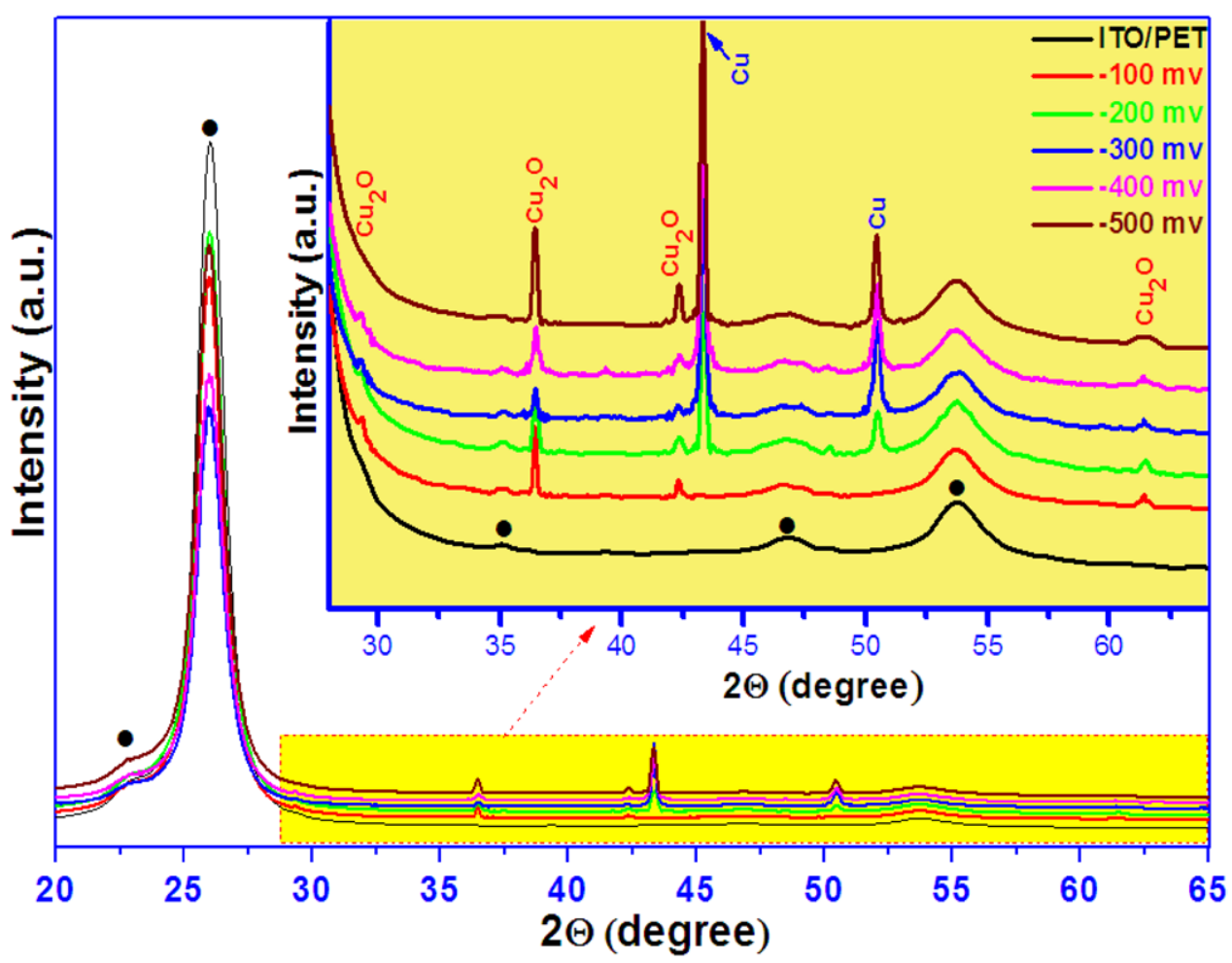

Figure 1. XRD patterns for films electrochemically deposited under different applied potential: () Reflections of ITO/PET substrate.

At deposition potential $-100 \mathrm{mV}, \mathrm{XRD}$ spectra shows peaks at $2 \theta$ values of $29.58^{\circ}, 36.43^{\circ}, 42.32^{\circ}$ and $61.39^{\circ}$ corresponding to the diffraction from (110), (11 1), (200) and (220) crystal plans of $\mathrm{Cu}_{2} \mathrm{O}$ in addition to the PET/ITO peaks. With the potential increasing up to $-500 \mathrm{mV}$, XRD spectra exhibits additional peaks at $2 \theta$ values of $43.40^{\circ}$ and $50.55^{\circ}$ corresponding to the reflection from (111) and (200) atomic plans of $\mathrm{Cu}$ in addition to the peaks corresponding to the $\mathrm{Cu}_{2} \mathrm{O}$ and PET/ITO substrate. Thus, the appropriate potential for $\mathrm{Cu}_{2} \mathrm{O}$ deposition is $-100 \mathrm{mV}$ versus $\mathrm{Ag} / \mathrm{AgCl}$ electrode.

The prepared $\mathrm{Cu}_{2} \mathrm{O}$ films grown on ITO/Glass, ITO/PET and FTO/Glass substrates were examined by x-ray diffraction. Their diffraction patterns as shown in figures $2(a)-(c)$ respectively indicates the presence of single-phase crystalline $\mathrm{Cu}_{2} \mathrm{O}$ films. All diffraction peaks (at $2 \theta=29.58^{\circ}$, $36.43^{\circ}, 42.32^{\circ}$, and $61.39^{\circ}$ that correspond to the $(110)$, (1 111$),(200)$, and (220) planes of cubic $\mathrm{Cu}_{2} \mathrm{O}$, respectively) are indexed to the standard structure of $\mathrm{Cu}_{2} \mathrm{O}$, JCPDS card No. 05-0667. There are no impurity peaks from copper metal or cupric oxide present in these patterns. The XRD peak intensity ratio of $\mathrm{I}(111) / \mathrm{I}(200)$ for the two strongest peaks is plotted as a function of the conductive substrate (working electrode), as shown in figure $2(d)$, since the standard diffraction intensity ratio of the (1 111$)$ peak to the $(200)$ peak is 2.88. For $\mathrm{Cu}_{2} \mathrm{O}$ films grown on ITO/Glass, the XRD spectra indicates an intensification of preferred (111) orientation with intensity ratio (4.29) [21]. $\mathrm{Cu}_{2} \mathrm{O}$ films grown on ITO/ PET shows relatively (111) preferred crystal plane than (200)orientationwith intensity ratio (2.23) [17]. But in the case of prepared $\mathrm{Cu}_{2} \mathrm{O}$ films grown on FTO/Glass substrates, it has good crystallinity with (200)-preferred orientation with intensity ratio $(0.21)[22,23]$. According to the XRD results, the substrate materials play a crucial role in the formation of $\mathrm{Cu}_{2} \mathrm{O}$ [19].

3.1.2. SEM. Figure 3 shows SEM images of $\mathrm{Cu}_{2} \mathrm{O}$ thin films grown on different (conductive substrates) working electrodes at $-100 \mathrm{mV}$. As can be seen, the working electrode plays an important role on the morphology of the deposit [18, 19]. Using these identical conditions described here, three distinct morphological manifestations were observed: (i) figure $3\left(\mathrm{~A}_{2}\right)$ and $\left(\mathrm{A}_{3}\right)$ show Fernlike Stellar Dendritic growth of $\mathrm{Cu}_{2} \mathrm{O}$ crystals on ITO/Glass substrate; there are six branches and side branches structure spread along the $\geq 110>$ directions where the crystal plane (111) is parallel to the ITO/Glass substrate surface. Herein, the lateral growth to dendrite branches is more favored than new nucleation site [15], (ii) another typical dendrite-like-crystal grow on FTO/Glass substrate as shown in figure $3\left(\mathrm{~B}_{2}\right)$ and $\left(\mathrm{B}_{3}\right)$; Four branched dendritic formed the crystal body. Moreover, each branch divaricated as dendrite branches and these branched dendrites linked together to form the crystal [24]. Dendritic crystals are developed to truncated octahedral crystals due to the acetate ions in the buffer preferentially adsorbing $\{111\}$ planes slowing down crystal growth along the $\langle 111\rangle$ directions normal to the substrate [24]. In summary, for ITO/Glass and FTO/Glass substrates, the lateral growth $\mathrm{Cu}_{2} \mathrm{O}$ film is preferable over increasing thickness. This was mainly due to fact that the FTO \& ITO/Glass are much more conductive than the semiconductive $\mathrm{Cu}_{2} \mathrm{O}$, resulting in the electrodeposition on the conductive substrate being faster than the growth out of the substrate [17]. (iii) For ITO/ PET substrate, figure $3\left(\mathrm{C}_{2}\right)$ and $\left(\mathrm{C}_{3}\right)$ showed $\mathrm{Cu}_{2} \mathrm{O}$ growth as $\{100\}$ facets truncated octahedral grained structure film with complete surface coverage, this mean that the deposited $\underline{\mathrm{Cu} 2 \mathrm{O}}$ 

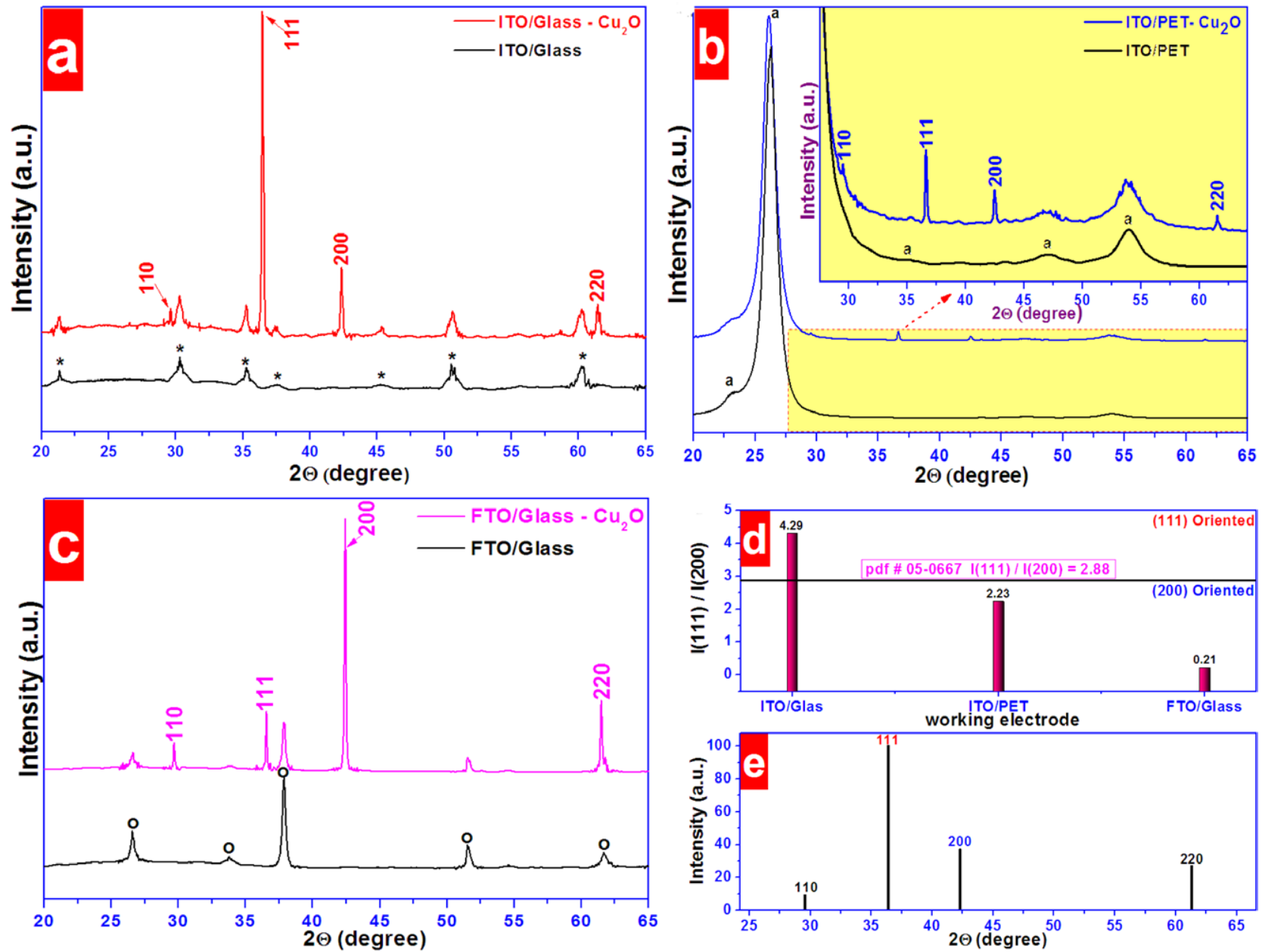

Figure 2. XRD patterns of (a) ITO/Glass \& ITO/Glass- $\mathrm{Cu}_{2} \mathrm{O}$, (b) ITO/PET \&ITO/PET-Cu $2 \mathrm{O},(c) \mathrm{FTO} / \mathrm{Glass} \& \mathrm{FTO} / \mathrm{Glass}-\mathrm{Cu} \mathrm{O}_{2} \mathrm{O}$, $(d) \mathrm{Plot}$ of relative peak intensity of $\mathrm{I}(111) / \mathrm{I}(200)$ as a function of working electrodeand $(e)$ reflections of $\mathrm{Cu}_{2} \mathrm{O}$ according to the JCPDS card No. 05-0667.

ad-atoms have good contact with the surface. This influences the final shapes of the crystals. As such, the growth mechanism is proposed as follows. When the $\underline{\mathrm{Cu} 2 \mathrm{O}}$ crystal is electrodeposited on ITO/PET, nuclei with different orientations may form in adjacent sites on the polycrystalline surface. Then, all nuclei competitively grow, leading to interpenetration and suppression of growth. This leads to the production of crystalline structure with irregular shapes [23]. These changes observed in cuprite $\mathrm{Cu}_{2} \mathrm{O}$ film morphology with different (conductive substrate) working electrode can be explained on the basis of growth and nucleation; Fleischmann and Thirsk proposed that a majority of the nucleation process can be divided into two categories:(a) progressive nucleation and (b) Instantaneous nucleation [25]. This is closely stratified by the current density as a function of film growth time given below. (see the online supporting information, figures S1-S3 (stacks.iop.org/000/000/000)).

Figure 4 showsthe current density for a constant growth potential is plotted as a function of time. The behavior of current transient curves illustrates the two main regimes which were used to grow the crystals. The ITO/PET substrate leads to a continuously rising current and hence slow growth of the crystals (kinetically limited growth). ITO/Glass, FTO/ Glass show also rising current but a decrease thereafter this mean progressive nucleation followed by diffusion limited growth [25]. the current density- $t$ characteristics of the $\mathrm{Cu}_{2} \mathrm{O}$ growth also showed that the current densities decreased with changing the substrate in this order ITO/PET, FTO/Glass and ITO/Glass respectively, the morphology of $\mathrm{Cu}_{2} \mathrm{O}$ tuned from facet shaped to branched, which is consistent with the results reported by [18, 24]. For FTO/Glass and ITO/Glass substrates a mode of sparse $\mathrm{Cu}_{2}$ Onucleation and lateral growth is dominant, as indicated by a lower current density during the nucleation stage (see figure 4, inset) and reflected by the branched film morphology (figure 3). This is due to $\mathrm{Cu}^{2+}$ ions near the $\mathrm{Cu}_{2} \mathrm{O}$ nuclei are consumed, forming a concentric diffusion field at the initial stage of deposition [18]. A depletion zone is formed around the growing $\mathrm{Cu}_{2} \mathrm{O}$ crystal when the deposition rate is faster than the diffusion rate of the nutrient $\mathrm{Cu}^{2+}$ ions. Once the depletion zone is formed, the apexes of a polyhedral crystal grow faster than the central parts of the facets and thus, branches are formed. Therefore, branched crystals are produced at low currents because of the limitation of the transportation of $\mathrm{Cu}^{2+}$ ions [24]. For ITO/PET, substrate $\mathrm{Cu}_{2} \mathrm{O}$ deposited at high current density, the transportation of $\mathrm{Cu}^{2+}$ is enhanced and the possibility of branching decreases by a more-pronounced fillinginprocess to seal the gaps between 


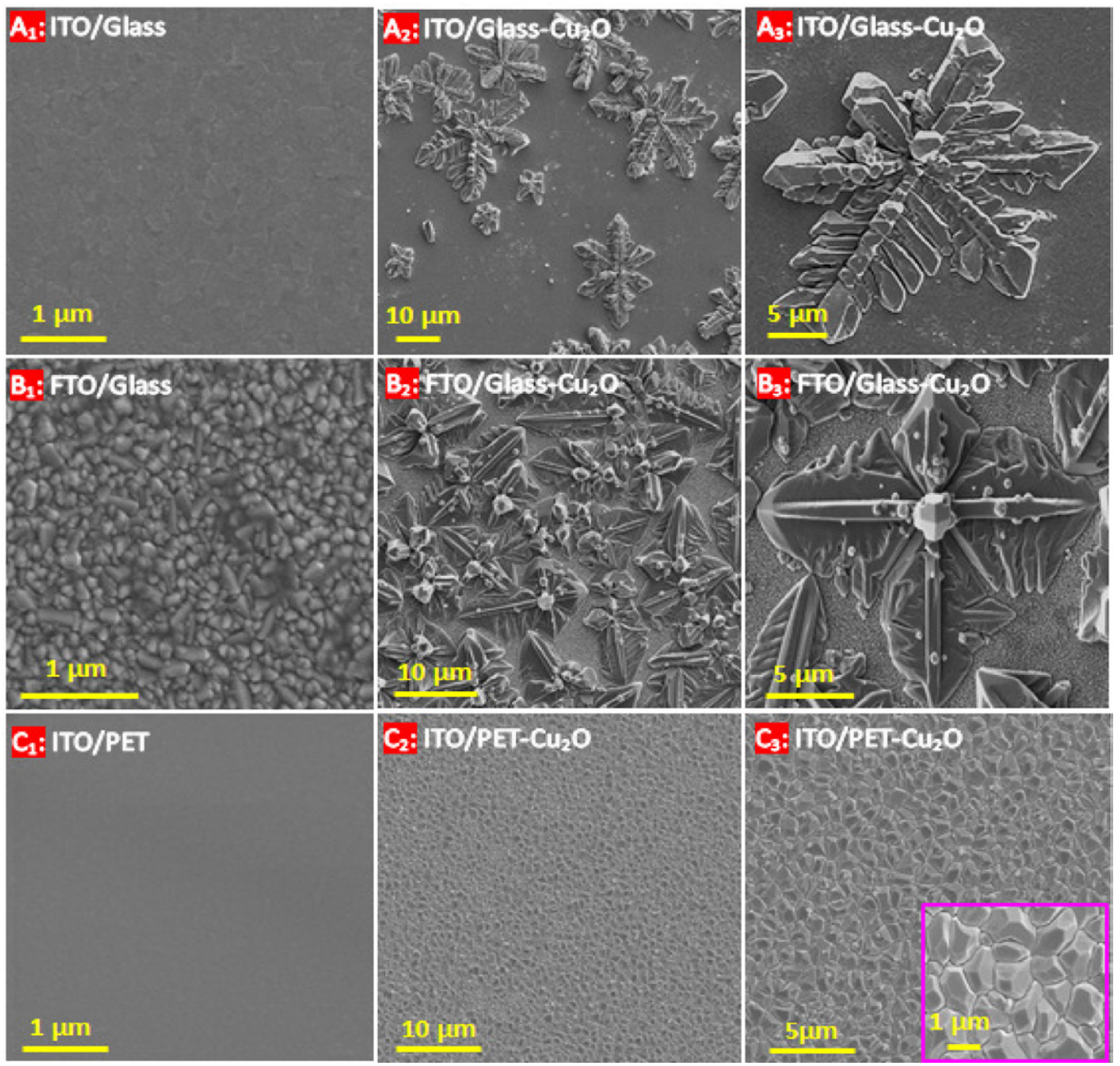

Figure 3. Top view $\mathrm{SEM}$ images of $\mathrm{Cu}_{2} \mathrm{O}$ films electrodeposited from copper (II) acetate/sodium acetate solutions at $\mathrm{pH}=5.6$ for different working electrode $\left(\mathrm{A}_{1}\right)$ ITO/Glass, $\left(\mathrm{A}_{2}, \mathrm{~A}_{3}\right)$ ITO/Glass-Cu $\mathrm{Cu}_{2} \mathrm{O},\left(\mathrm{B}_{1}\right) \mathrm{FTO} / \mathrm{Glass},\left(\mathrm{B}_{2}, \mathrm{~B}_{3}\right) \mathrm{FTO} / \mathrm{Glass}-\mathrm{Cu}_{2} \mathrm{Oand}\left(\mathrm{C}_{1}\right) \mathrm{ITO} / \mathrm{PET},\left(\mathrm{C}_{2}, \mathrm{C}_{3}\right)$ ITO/ PET- $-\mathrm{Cu}_{2} \mathrm{O}$.

the branches and thus, thegreater density of faceted crystal nucleation sites is favorableresulting in a more compact, dense $\mathrm{Cu}_{2} \mathrm{O}$ morphology [24].

\subsection{Electrochemical impedance spectroscopy (EIS)}

The EIS analysis was carried out for the cell within the frequency range of $10^{5}-10^{-1} \mathrm{~Hz}$ at the perturbation potential of $20 \mathrm{mV}$. Figure 5 shows the results of EIS measurement in this study including the Nyquist plot ( $\mathrm{Z}$ imaginary $\left[\mathrm{Z}^{\prime \prime}\right]$ versus $\mathrm{Z}$ real $\left[\mathrm{Z}^{\prime}\right]$, figure $5(a)$, phase angle $(-\Psi$ versus $\log$ $f$, figure $5(b))$, bode plot $(\log |\mathrm{Z}|$ versus $\log f$, figure $5(c)$ ) and admittance plot (Y imaginary [ $\left.\mathrm{Y}^{\prime \prime}\right]$ versus $\mathrm{Y}$ real $\left[\mathrm{Y}^{\prime}\right]$, figure $5(d)$ ) for prepared samples. The impedance spectra were fitted with two-time constant parallel model (2TP) equivalent circuit $\left[R_{\mathrm{S}}\left(\mathrm{CPE} 1\left(R_{\mathrm{SEI}}\left(\operatorname{CPE} 2\left(R_{\mathrm{ct}} W\right)\right)\right)\right)\right]$ shown in figure $5(e)$, which represents the modified model originally proposed by Meyers et al [26]for porous electrodes. Here, $R_{\mathrm{S}}, R_{\mathrm{SEI}}$ and $R_{\text {ct }}$ represent the high frequency limit series impedance, usually respectively associated with theelectrolyte resistance, the resistance of the film and the charge transfer resistance. The use of a CPE is required due to the distribution of the relaxation times as a result of inhomogeneities present at a micro or nano (atomic/molecular) level, such as the surface roughness/ porosity [27]. The CPE approach was used to fit EIS experimental spectra, the capacitance of double layer represented by constant phase element CPE2 $\left(C_{\mathrm{dl}}\right)$, while the fitting procedure showed that the exponent of CPE1 element gave the value of unity. Hence, in this case the CPE1 element was replaced by the pure capacitance, $C_{\mathrm{SEI}}$. In the low frequency region, linear spike modeled by Warburg impedance (w) was related to the resistance against the diffusion of supporting electrolyte ions through the pores of the oxide film in the electrolyte $/ \mathrm{Cu}_{2} \mathrm{O}$ layer/electrode configuration [28].

In figure 5(a) and the inset, the Nyquist plot consisted of (i) the higher frequency region, a very small semicircle corresponding to the capacitance and the resistance of the solid-electrolyte interface layer (SEI). This capacitance and resistance are formed due to the reaction between the electrolyte and the surface of the electrode, (ii) the mid-low 


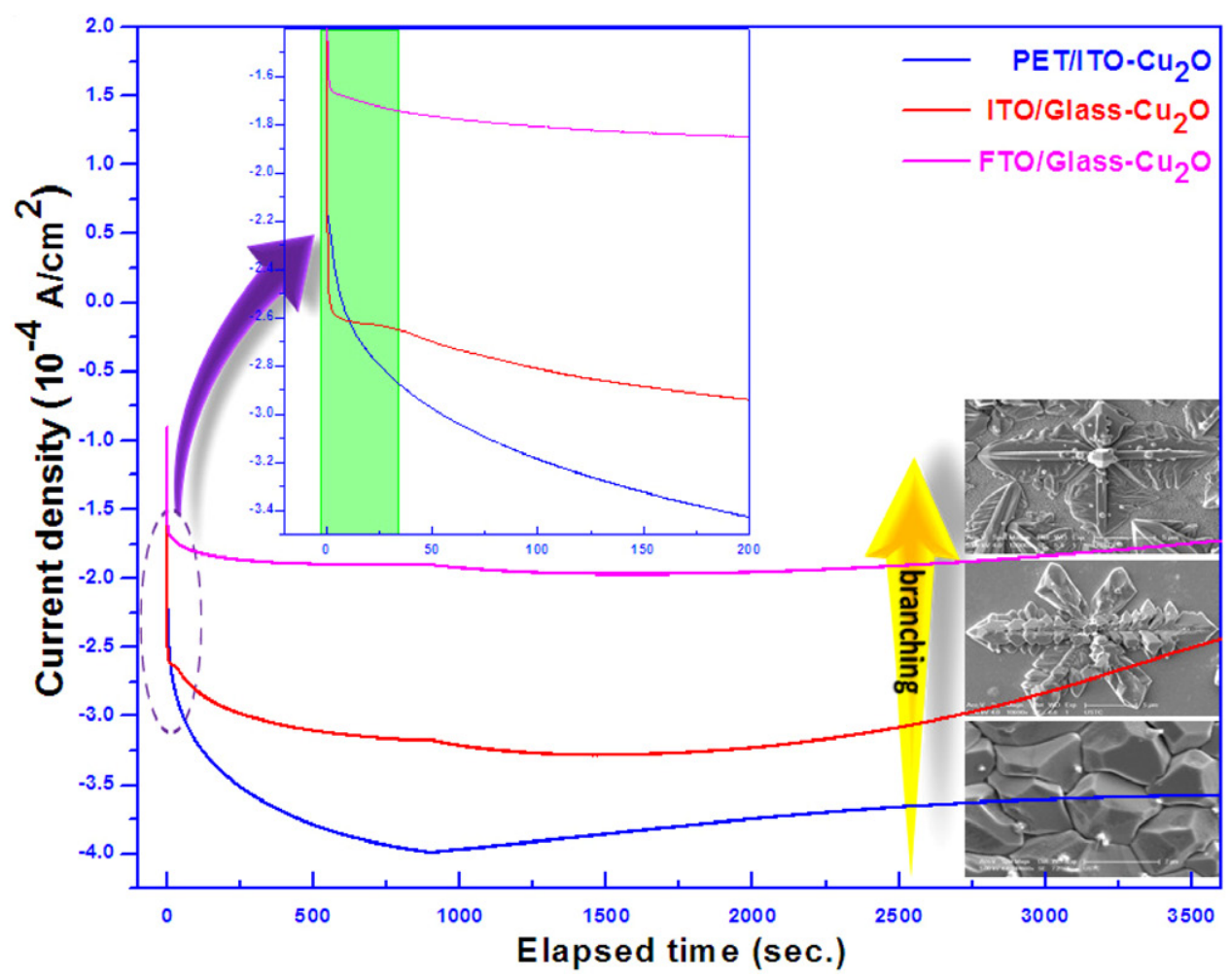

Figure 4. Current density versus film growth time for $\mathrm{Cu}_{2} \mathrm{O}$ fillms electrodeposited on; FTO/Glass, ITO/Glass and ITO/PET.

frequency region; a large semicircle corresponding to double layer capacitance and the charge transfer resistance, which is followed by a straight line. The linear portion (with approximately 45 angle) observed in the low-frequency range, implies a mass-transfer limited process, where the double layer capacitance $\left(C_{\mathrm{dl}}\right)$ is impermeable and the current flows exclusively via the Faradaic branch of the circuit (see the online supporting information, figures S4 and S5 (stacks. iop.org/000/000/000)). The diffusion is the slowest event and therefore the Warburg impedance $\mathrm{W}$, which represents the diffusion of a redox species, dominates the impedance at low frequencies [29].

From The values of the electrochemical impedance parameters obtained from the fitting procedure listed in table 1 , it is observed that the semicircle diameter of FTO/Glass- $\mathrm{Cu}_{2} \mathrm{O}$ electrode is shorter than that of the other electrodes, implying the charge transfer resistance (Rct) of FTO/Glass- $\mathrm{Cu}_{2} \mathrm{O}$ exhibits the lowest value, This means that FTO/Glass $-\mathrm{Cu}_{2} \mathrm{O}$ possesses the highest charge transfer efficiency [30]. Figure 5(b) shows the relation between the frequency and phase angle plot. At low frequency region; the minimum phase angle ranges from $65-80^{\circ}$, which is less than the expected $90^{\circ}$ of an ideal capacitive behavior. The slopes of the Bode plots ( $\log Z$ versus $\log f$, figure $5(c)$ are less than unity, indicative of pseudocapacitivebehavior [31].

Furthermore, figure $5(d)$ shows the admittance plot of ITO/ PET- $\mathrm{Cu}_{2} \mathrm{O}$, ITO/Glass- $\mathrm{Cu}_{2} \mathrm{O}$ and $\mathrm{FTO} / \mathrm{Glass}-\mathrm{Cu}_{2} \mathrm{O}$, which is generally characterized by knee frequency. The observed knee frequencies are $0.82,8.1$ and $14.6 \mathrm{KHz}$, respectively.The knee frequency defines the maximum frequency at which the resistive behavior becomes negligible and the capacitive behavior becomes dominant. It can be seen that the FTO/Glass- $\mathrm{Cu}_{2} \mathrm{O}$ displays higher knee frequency than the others which further substantiates the lower charge transfer resistance [32].

The capacitance versus potential $(C-V)$ measurement was also employed to determine the conduction type of the cuprous oxide films, the flat band $\left(E_{\mathrm{fb}}\right)$ and carrier density $\left(N_{\mathrm{A}}\right)$, which can be obtained in a Mott-Schottky (MS) plot with $1 / C^{2}$ Versus potential at a fixed frequency of $1 \mathrm{kHz}$. The capacitance-potential measurements are presented as a MS plot in following the equation:

$$
\frac{1}{C^{2}}=\frac{2}{N_{A} e \varepsilon \varepsilon_{0}}\left[\left(E-E_{\mathrm{fb}}\right)-\frac{K T}{e}\right]
$$

In equation (4), $C$ is the interfacial capacitance, $\varepsilon$ is the dielectric constant of $\mathrm{Cu}_{2} \mathrm{O}$ (taken as 7.5 [33],), $\varepsilon_{0}$ is the permittivity of free space, $N_{\mathrm{A}}$ is the number density of acceptors in $\mathrm{Cu}_{2} \mathrm{O}$ (doping level), $E$ is the applied potential, $E_{\mathrm{fb}}$ is the flat band potential, $T$ is the absolute temperature $(298 \mathrm{~K}), k$ is the Boltzmann constant, and $e$ is the electron charge. Apparently, the conduction type may be identified by the sign of its MottSchottky plot ( $1 / C^{2}$ versus $\mathrm{V}$ plot); a positive slope indicates an $n$-type semiconductor, while a negative slope points to a p-type semiconductor [34]. The Mott-Schottky plots are presented in figure 6 . As shown, the samples show positive slopes, indicating that these cuprous oxide films are $n$-type semiconductors. From the slope $=2 / \varepsilon \varepsilon_{0} e N_{\mathrm{A}}$ and intercept at $1 / C^{2}=$ 0 , the donor density $\left(N_{\mathrm{A}}\right)$ and the flat-band potential $\left(E_{\mathrm{fb}}\right)$ of an $n$-type semiconductor can be obtained, respectively. For the $\mathrm{Cu}_{2} \mathrm{O}$ film deposited on ITO/PET, ITO/Glass and FTO/ Glassconducive substrates, the measured flat band potentials and charge carrier densities were $-0.36,-0.44$ and $-0.55 \mathrm{~V}$ 

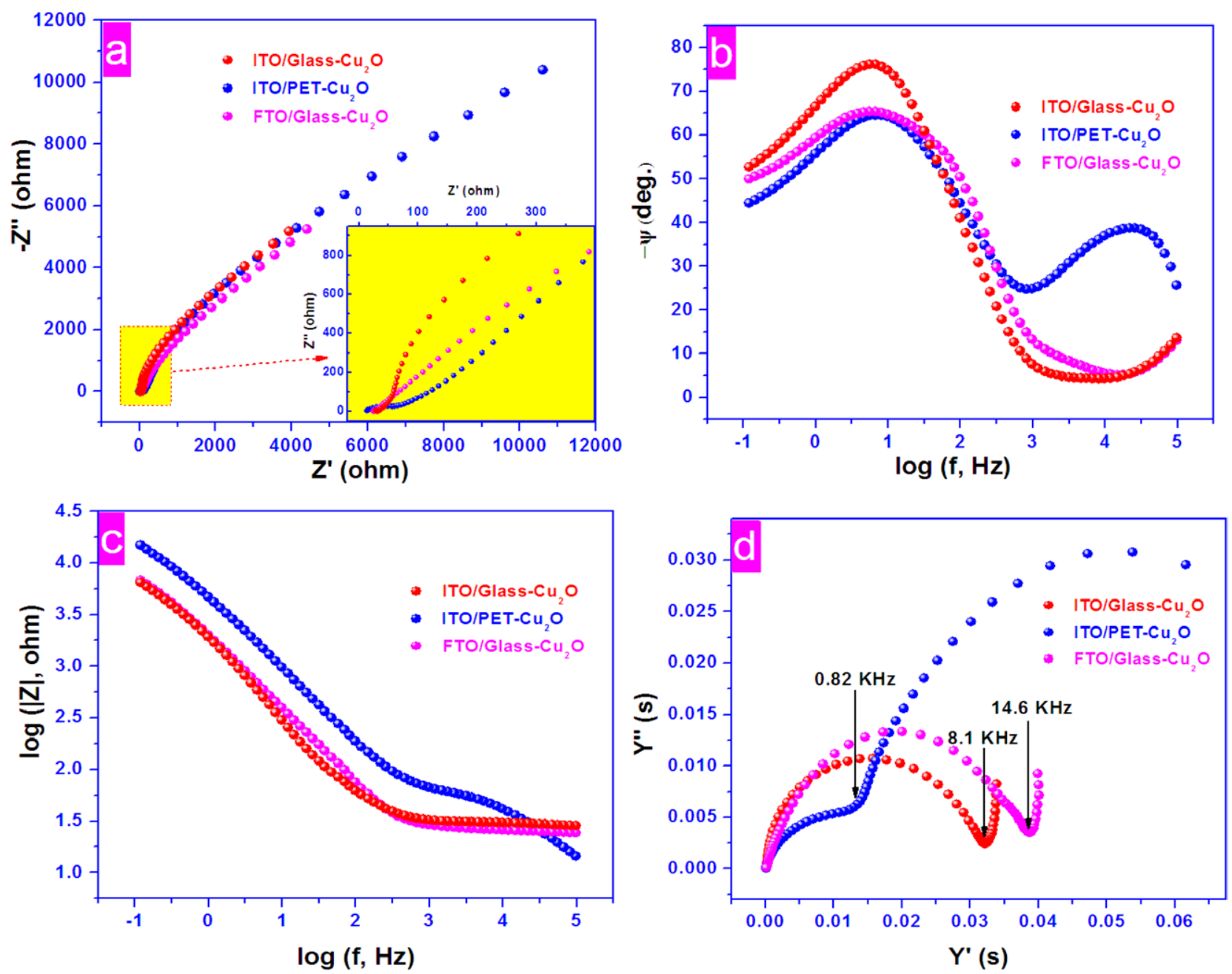

e

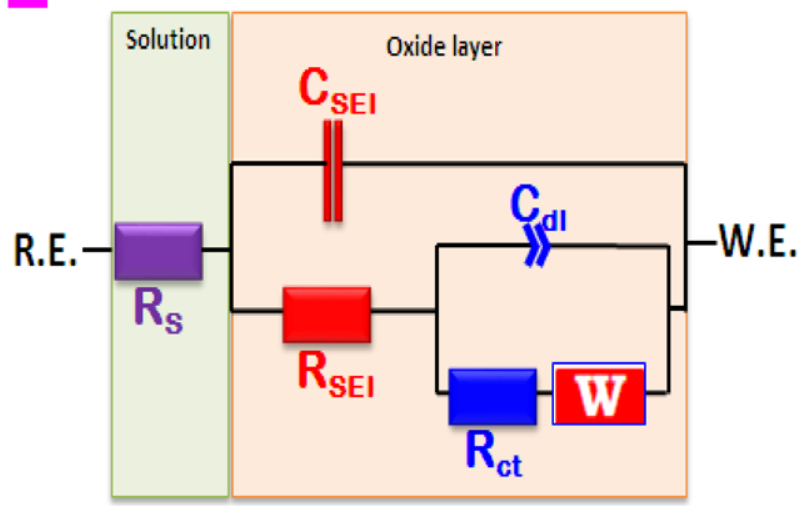

Figure 5. Nyquist plot, Bode plots and admittance plot for $\mathrm{Cu}_{2} \mathrm{O}$ thin film growing on (ITO/PET, ITO/Glass and FTO/Glass); (a) Nyquist plots; (Z imaginary versus $\mathrm{Z}$ real), $(b)$ Bode phase plots; $(-\Psi$ versus $\log$ f), $(c)$ Bode modulus plots; $(\log \mid \mathrm{Zl}$ versus $\log f),(d)$ admittance plot; (Y imaginary versus Y real) and (e) Equivalent electric circuits.

Table 1. The parameters obtained from the fitting of the equivalent electric circuit to the experimental impedance data obtained for different substrates.

\begin{tabular}{llllllll}
\hline & $R_{\mathrm{S}}\left(\Omega . \mathrm{cm}^{2}\right)$ & $C_{\mathrm{SEI}}\left(\mathrm{Fcm}^{-2}\right)$ & $R_{\mathrm{SEI}}\left(\Omega . \mathrm{cm}^{2}\right)$ & $C_{\mathrm{dl}}\left({\left.\mathrm{S} . \mathrm{s}^{\mathrm{n}} \mathrm{cm}^{-2}\right)}\right)$ & $n$ & $R_{\mathrm{ct}}\left(\Omega . \mathrm{cm}^{2}\right)$ & $W\left(\mathrm{~S} . \mathrm{s}^{0.5} \mathrm{~cm}^{-2}\right)$ \\
\hline G/ITO & 19.14 & $1.08 \times 10^{-7}$ & 12.66 & $9.66 \times 10^{-5}$ & 0.8582 & $0.58 \times 10^{4}$ & $14.49 \times 10^{-5}$ \\
G/FTO & 13.05 & $0.66 \times 10^{-7}$ & 12.94 & $9.00 \times 10^{-5}$ & 0.8082 & $0.40 \times 10^{4}$ & $12.46 \times 10^{-5}$ \\
P/ ITO & 13.13 & $2.92 \times 10^{-7}$ & 46.56 & $4.64 \times 10^{-5}$ & 0.7567 & $1.74 \times 10^{4}$ & $9.584 \times 10^{-5}$ \\
\hline
\end{tabular}



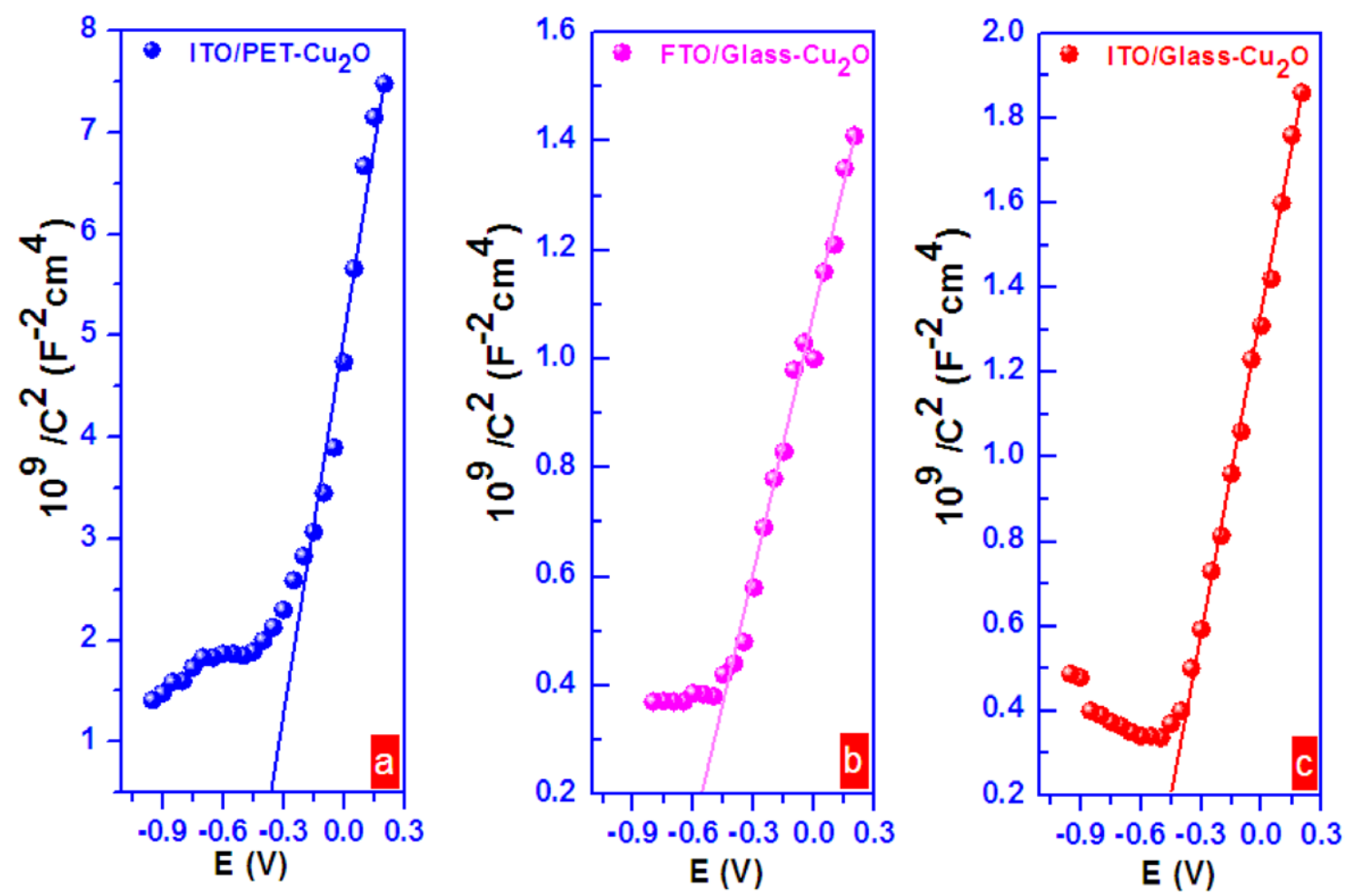

Figure 6. Mott-Schottky plots of $\mathrm{Cu}_{2} \mathrm{O}$ films deposited on $(a)$ ITO/PET, $(b)$ FTO/Glass and $(c)$ ITO/Glass.

versus $\mathrm{Ag} / \mathrm{AgCl}$ and $1.4 \times 10^{18}, 7 \times 10^{18}$ and $1.2 \times 10^{19} \mathrm{~cm}^{-3}$ respectively. These values, although high for a typical semiconductor, agree with the previously reported values for $\mathrm{Cu}_{2} \mathrm{O}$ films synthesized through different methods $[35,36]$.

\section{Conclusions}

In summary, we have examined the fabrication of $\mathrm{Cu}_{2} \mathrm{O}$ films with electrochemical deposition by selecting different conductive substrates as working electrodes and successfully found that the choice of substratematerials hasa crucial role in controlling the $\mathrm{Cu}_{2} \mathrm{O}$ growth without any additives or buffers. The morphology of the $\mathrm{Cu}_{2} \mathrm{O}$ films deposited on (ITO/ Glass, FTO/Glass and ITO/PET) was investigated. Fernlike Stellar Dendritesof preferred (1 111 ) orientation formed on ITO/Glass substrate, another typical dendrite like-crystalhas good crystallinity with (200)-preferred orientation deposited on FTO/Glass and faceted, more dense and truncated polyhedral grained structure with different relatively (1 111 ) preferred crystal plane than (200) when it was grown on ITO/PET. The Electrochemical impedance spectroscopy (EIS) implies that the impedance results reveal frequency dispersion fitted with the two-time constant parallel model (2TP). From the values of the electrochemical impedance parameters obtained from the fitting procedure, the charge transfer resistance (Rct) of FTO/Glass- $\mathrm{Cu}_{2} \mathrm{O}$ exhibits the lowest value confirmed with high knee frequency than the others in the admittance plot. This means that FTO/Glass$\mathrm{Cu}_{2} \mathrm{O}$ possesses the highest electron transfer efficiency. Finally, The Mott-Schottky plot shows that all the films are $n$-type semiconductors.

\section{Acknowledgment}

The authors would like to acknowledge the financial support ofthe Egyptian Government (cultural affairs \& missions sector).

\section{References}

[1] Siripala W, Ivanovskaya A, Jaramillo T F, Baeck S-H and McFarland E W 2003 Sol. Energy Mater. Sol. Cells 77229

[2] Mahalingam T, Chitra J S P, Chu J P, Moon H, Kwon H J and Kim Y D 2006 J. Mater. Sci. Mater. Electron. 17519

[3] Lim K, Park J, Kim D-G, Kim J-K, Kang J-W and Kang Y-C 2012 Appl. Surf. Sci. 2589054

[4] Shishiyanu S T, Shishiyanu T S and Lupan O I 2006 Sensors Actuators B-Chem. 113468

[5] Wang Y, Liu L, Cai Y, Chen J and Yao J 2013 Appl. Surf. Sci. 270245

[6] Suhr H and Holzschuh H 1990 Appl. Phys. A 51486

[7] Ray S C 2001 Sol. Energy Mater. Sol. Cells 68307

[8] Mizuno K, Izaki M, Murase K, Shinagawa T, Chigane M, Inaba M, Tasaka A and Awakura Y 2005 J. Electrochem. Soc. 152 C179

[9] Matthew J, Siefried J and Choi K S 2004 Adv. Mater. 161743

[10] Jeong S and Aydil E S 2009 J. Cryst. Growth 3114188

[11] Dharmadasa I M and Haigh J 2006 J. Electrochem. Soc. 153 G47

[12] Ai Z, Xiao H, Mei T, Liu J, Zhang L, Deng K and Qiu J 2008 J. Phys. Chem. C 11211929

[13] Sun S and Yang Z 2014 RSC Adv. 43804

[14] Luo Y, Li S, Ren Q, Liu J, Xing L, Wang Y, Yu Y, Jia Z and Li J 2007 Cryst. Growth Des. 787

[15] Zhao W, Fu W, Yang H, Tian C, Li M, Li Y, Zhang L, Sui Y, Zhou X, Chen H and Zou G 2011 CrystEngComm 132871

[16] Osherov A, Zhu C and Panzer M J 2013 Chem. Mater. 25692 
[17] Wei H M, Gong H B, Chen L, Zi M and Cao B Q 2012 J. Phys. Chem. C 11610510

[18] Osherov A, Zhu C and Panzer M J 2013 J. Phys. Chem. C 11724937

[19] Liu Y L, Liu Y C, Mu R, Yang H, Shao C L, Zhang J Y, Lu Y M, Shen D Z and Fan X W 2005 Semicond. Sci. Technol. 2044

[20] Sun F, Guo Y, Tian Y, Zhang J, Lv X, Li M, Zheng Y and Wang Z 2008 J. Cryst. Growth. 310318

[21] Bijani S, Martı́nez L, Gaba's M, Dalchiele E A and Ramos-Barrado J-R 2009 J. Phys. Chem. C 11319482

[22] Grez P, Herrera F, Riveros G, Ramírez A, Henríquez R, Dalchiele E and Schrebler R 2012 Phys. Status Solidi a 2092470

[23] Yao Z Q, Liu S L, Zhang L, He B, Kumar A, Jiang X, Zhang W J and Shao G 2012 Appl. Phys. Lett. 101042114

[24] Xue J, Liang W, Liu X, Shen Q and Xu B 2012 Cryst. Eng. Comm. 148017

[25] Pandey R K, Chandra S and Sahu S N 1996 1st edn (New York: Dekker)
[26] Meyers J P, Doyle M, Darling R M and Newmana J 2000 J. Electrochem. Soc. 1472930

[27] Talha M, Behera C K, Kumar S, Pal O, Singh G and Sinha O P 2014 RSC Adv. 413340

[28] Navarro-Flores E, Chong Z and Omanovic S 2005 J. Mol. Catal. A: Chem. 226179

[29] Zhou H, Lou F, Vullum P E, Einarsrud M A, Chen D and Vullum-Bruer F 2013 Nanotechnology 24435703

[30] Kang S-Z, Liu H, Li X, Sun M and Mu J 2014 RSC Adv. 4538

[31] Nkosi D, Pillay J, Ozoemena K I, Nouneh K and Oyama M 2010 Phys. Chem. Chem. Phys. 12604

[32] Senthilkumar S T, Selvan R K, Ponpandian N and Melo J S 2012 RSC Adv. 28937

[33] Li C, Li Y and Delaunay J J 2014 ACS Appl. Mater. Interfaces 6480

[34] Zhang Z and Wang P 2012 J. Mater. Chem. 222456

[35] Laidoudi S, Bioud A Y, Azizi A, Schmerber G, Bartringer J, Barre S and Dinia A 2013 Semicond. Sci. Technol. 28115005

[36] Wang L and Tao M 2007 Electrochem. Solid-State Lett. 10 H248 


\section{QUERIES}

\section{Page 1}

AQ1

Please be aware that the colour figures in this article will only appear in colour in the web version. If you require colour in the printed journal and have not previously arranged it, please contact the Production Editor now.

Page 4

AQ2

Please note that we have retained the 'Supplementary information' as is. Please confirm whether this is alright.

Page 6

AQ3

We have changed an equation number as per sequential order. Please check and approve.

Page 8

AQ4

Please check the details for any journal references that do not have a link as they may contain some incorrect information. 